\title{
Functional morphology of the forelimb musculature reflects flight and foraging styles in aquatic birds
}

\author{
Fernanda Bribiesca-Contreras ${ }^{1,3}$ (D) $\cdot$ Ben Parslew $^{2} \cdot$ William I. Sellers $^{1}$ (D)
}

Received: 26 June 2019 / Revised: 19 January 2021 / Accepted: 19 February 2021 / Published online: 18 March 2021

(c) The Author(s) 2021

\begin{abstract}
Aquatic birds show a great diversity of locomotion styles and wing morphologies, from penguins that are fully specialized for an aquatic life to species of aerial flyers that also use their wings for underwater propulsion (e.g. auks and shearwaters). Moving between the air-water interface exerts conflicting pressures on the body and wing anatomy of diving birds. In this work, we investigated the functional morphology of the forelimb musculature of 18 species of aquatic birds that display a variety of flight and foraging styles. Muscle architecture was related to function, with special emphasis on muscle mass. Dissections of one of the forelimbs of 20 specimens of waterbirds were performed to obtain numerical data of muscle architecture. Total wing muscle mass scaled isometrically to body mass ${ }^{1.0}$, whereas fascicle length scaled to muscle mass ${ }^{0.284}$, which is consistent with previous results of scaling in wings of raptors. A principal component analysis (PCA) of normalised muscle masses resulted in a biplot where three main morphological groups can be distinguished. Anatids (ducks and geese) occupy a space represented by muscles that are activated during downstroke. Auks and penguins clustered together in a region dominated by muscles that assist in wing elevation and showed a degree of hypertrophy. The rest of the species grouped together in the lower limits of both PCs where muscles that facilitate wing flexion-extension and stabilisation are loaded. The distribution of mass in the wing muscles of the aquatic birds seemed to be related to flight and foraging style and showed non-significant influence of shared phylogenetic history (Kmult: $0.71, p$ value: $0.083,10,000$ permutations).
\end{abstract}

Keywords Wing $\cdot$ Aquatic birds $\cdot$ Diving $\cdot$ Muscle architecture

\section{Zusammenfassung}

Die funktionelle Morphologie der Flügelmuskulatur spiegelt bei Wasservögeln Flugstil und Art der Nahrungssuche wider.

Wasservögel zeigen eine große Bandbreite von Fortbewegungsarten und Flügelmorphologien: von völlig auf ein aquatisches Leben spezialisierten Pinguinen bis hin zu guten Fliegern, welche ihre Flügel auch zum Antrieb unter Wasser gebrauchen (beispielweise Alke und Sturmtaucher). Der Grenzübertritt zwischen Luft und Wasser übt bei Tauchvögeln gegensätzliche Drücke auf Körper und Flügelanatomie aus. In dieser Arbeit untersuchten wir die funktionelle Morphologie der Flügelmuskulatur von 18 Wasservogelarten, welche ein breites Spektrum an Flugstilen und Arten der Nahrungssuche aufweisen.

Communicated by A. Hedenström.

Fernanda Bribiesca-Contreras

bribiesca@is.mpg.de

1 Department of Earth and Environmental Sciences, University of Manchester, Michael Smith Building, Manchester M13 9PT, England

2 School of Mechanical, Aerospace and Civil Engineering, University of Manchester, Pariser Building, Manchester M13 9PL, England

3 Present Address: Dynamic Locomotion Group, Max Planck Institute for Intelligent Systems, Stuttgart, Germany 
Die Bauweise der Muskulatur stand in Beziehung zur Funktion, wobei der Muskelmasse eine besondere Bedeutung zukam. Wir sezierten jeweils eine Vorderextremität von 20 Wasservogelindividuen, um Zahlenwerte zum Muskelbau zu erhalten. Die Gesamtmasse der Flügelmuskulatur stand in einem isometrischen Verhältnis von 1,0 zur Körpermasse, wohingegen die Länge der Faszikel in einem Verhältnis von 0,284 zur Muskelmasse stand, was sich mit früheren Ergebnissen zu den Verhältnissen bei Greifvogelflügeln deckt. Eine Hauptkomponentenanalyse (PCA; engl.: principal component analysis) der normalisierten Muskelmassen ergab ein Biplot, welches drei morphologische Hauptgruppen erkennen ließ. Anatiden (Enten und Gänse) belegten den Raum, der durch diejenigen Muskeln repräsentiert wird, welche während des Abschwungs aktiviert werden. Alke und Pinguine bildeten ein gemeinsames Cluster in der Region, in welcher diejenigen Muskeln dominieren, die am Heben des Flügels beteiligt sind, und zeigten ein gewisses Maß an Hypertrophie. Die verbleibenden Arten befanden sich in einer gemeinsamen Gruppe an den Untergrenzen beider Hauptkomponenten, wo die für die Beugung-Streckung und Stabilisierung des Flügels zuständigen Muskeln angesiedelt sind. Die Massenverteilung in der Flügelmuskulatur von Wasservögeln scheint im Zusammenhang mit dem Flugstil sowie der Art der Nahrungssuche zu stehen und zeigt einen nicht signifikanten Einfluss einer gemeinsamen phylogenetischen Geschichte (K mult: 0,711, p-Wert: 0,083, 10.000 Permutationen).

\section{Introduction}

Modern birds move through the terrestrial, aerial, and aquatic environments. Aquatic birds interact with all these environments to feed, spanning from flightless penguins that are highly specialized for an aquatic lifestyle to diving petrels and auks that perform both aerial and underwater locomotion by means of wing oscillations. Moving between the air and water environments puts conflicting pressures on an animal's anatomy that tends to maximize function in one medium relative to the other (Ropert-Coudert et al. 2004). While strictly aerial flying birds are under selection pressure to increase wing area while reducing body mass, due to the effects of gravity and aerodynamic forces acting on their body during flight (Kovacs and Meyers 2000), a larger body mass increases dive duration and efficiency in swimming birds (Elliot et al. 2010) and might reduce the locomotor costs of swimming by increasing inertial resistance to the buoyant force (Lovvorn and Jones 1991). Water is over 850 times denser than air with a density of $\sim 1.2 \times 10^{3} \mathrm{~kg} \mathrm{~m}^{-3}$, making hydrodynamic forces - both lift and drag-much greater for a given area and velocity, favouring shorter wings in diving species (Elliot et al. 2010). In species where aerial and underwater flight are employed (e.g. auks, diving petrels, and dippers), trade-offs in form and function are evident in their body plan and diving performance (Stettenheim 1959; Storer 1960; Spring 1971; Raikow et al. 1988; Elliott et al. 2013).

Aquatic birds show a great diversity of locomotor strategies while foraging (Ashmole 1971). Gaviiformes (loons and grebes) are medium-sized birds that primarily eat fish that they capture underwater by foot-propelled swimming (Townsend 1909). Procellariformes (petrels, albatrosses, and shearwaters) are a group of seabirds that feed almost exclusively in the pelagic habitat using a diverse range of foraging styles, from shearwaters that feed by swimming underwater using their feet and wings for propulsion (reaching depths of up to $\sim 60 \mathrm{~m}$ in the short-tailed shearwater
Ardenna tenuirostris; Weimerskirch and Cherel 1998) to prions that feed on zooplankton by hydroplaning or floating on the surface (Warham 1977; Brown et al. 1978; Pennycuick 1982; Klages and Cooper 1992). Sphenisciformes (penguins) are highly specialized for aquatic locomotion and have entirely lost the ability for aerial flight, using their hydrofoil-shaped wings for underwater propulsion (Clark and Bemis 1979; Schreiweis 1982). From the traditional clade of Pelecaniformes, gannets and boobies (Sulidae) are known for their remarkable plunge dives to enter the water and pursue their prey by foot and wing-propelled swimming (Nelson 1978); shags and cormorants (Phalacrocoracidae) forage by foot-propelled diving only after descending from the surface (Croxall et al. 1991; Watanuki et al. 2005). Within Charadriiformes (shorebirds), the alcids (Alcidae) are notable for their ability to pursue prey underwater using partially folded wings for propulsion (Spring 1971). The gulls (Laridae) are generalist birds that are well adapted for swimming, flying and walking (Pons et al. 2005). As an outgroup, we included the Anserinae (geese and swans) and Anatinae (dabbling ducks) that feed on the water surface.

Throughout the evolutionary history of birds, the anatomy of the pectoral girdle and forelimb has been modified in response to the physical demands imposed by flight. As a result, wing morphology in Aves is highly diverse and reflects aspects of life history (e.g. Rayner 1988; Brewer and Hertel 2007; Hedenström 2008; Simons 2010; Sievwright and Macleod 2012; Wang and Clarke 2014). Wing shape has been demonstrated to correlate with flight ability in Pelecaniformes (Brewer and Hertel 2007), Procellariformes (Warham 1977), and multiple species of seabirds (Spear and Ainley 1997a). Similarly, studies on the forelimb skeleton have shown patterns of variation related to foraging ecology in aquatic birds (Kuroda 1954; Livezey 1988, 1989; Habib 2010; Hinić-Frlog and Motani 2010; Simons 2010; Wang and Clarke 2014). Although substantial literature is available for some forelimb muscles of waterbirds, which provides insight into their role during different locomotor styles 
(Hartman 1961; Spring 1971; Goldspink et al. 1978; Rosser et al. 1994; Meyers 1997; Meyers and Mathias 1997; Ponganis et al. 1997; Torrella et al. 1998; Kovacs and Meyers 2000; Meyers and Stakebake 2005; Schroeder et al. 2015), our knowledge of the function of extrinsic and intrinsic musculature is still very limited in these birds. To our knowledge, only the study of Spring (1971) in species of murres (Uria aalge and $U$. lomvia) has considered the entirety of the wing and provided numerical data for weights of dried muscles. For this reason, we decided to investigate the functional morphology of the avian wing myology in species of aquatic birds and its relationship with locomotor modes.

The functional role of the wing muscles in aquatic birds has been investigated mainly in species that exhibit underwater swimming. Penguins show extreme modifications in their body plan that enhance underwater locomotion for their almost entirely aquatic lifestyle (Storer 1960; Bannasch 1995). A detailed anatomical study of the appendicular myology of different species of penguins by Schreiweis (1982) reported a configuration that is unique among extant birds. He reported the absence of multiple muscles in the penguin forelimb (e.g. biceps brachii $[\mathrm{BB}]$ and the pronator muscles) and reduction of intrinsic musculature to completely tendinous structures [e.g. flexor carpi ulnaris (FCU) and extensor digitorum communis (EDC)]. Furthermore, the supracoracoideus (SC) muscle, the main elevator in the avian wing, is enlarged in penguins (Baldwin 1988), which is related to the use of an active thrust-generating upstroke during diving (Clark and Bemis 1979). Spring (1971) compared the functional morphology of the skeleton and pelvic and wing musculature in two species of auks (U. aalge and $U$. lomvia). Their study reported a similar arrangement of forelimb muscles to that of other flying birds and suggested hypertrophy for a number of muscles (e.g. SC and scapulohumeralis caudalis [SHCa]). Similarly, an enlargement of $\mathrm{SC}$ in other species of wing-propelled divers in comparison to foot-propelled divers has been reported by Kovas and Meyers (2000), using their own data of the Atlantic puffin and that of Greenwalt (1962).

In this work, we compared the muscle architecture of the avian forelimb in species of aquatic birds exhibiting a variety of flight and foraging styles. Muscle architecture refers to the internal arrangement of muscle fibres within muscles and is a good predictor of function (Lieber and Fridén 2000). Under the principle that muscle mass is proportional to the amount of work and power that muscles can produce in a contracting cycle (Alexander 1992; Marsh 1999), we believe that the distribution of muscle mass in the avian wing is fundamental for understanding flight and might be associated with aquatic locomotion ability. The aims of our study are to determine whether muscle architecture reflects aspects of flight, swimming, and foraging behaviour, understand the functional role of individual muscles during flight and underwater-wing-propelled diving, and to evaluate the existence of any trade-offs in species that perform both aerial and underwater flight. We would expect that birds displaying a similar locomotion style would share patterns of mass distribution along their wing that are independent of their phylogenetic history. In this matter, we would expect that wing-propelled divers that also perform aerial flight (auks and shearwaters) occupy a morphological space that is intermediate between non-divers and penguins, with penguins occupying a unique morphological space due to their strictly aquatic lifestyle. We anticipate that the anatids would be isolated from the rest of the species and would occupy the opposite extreme to penguins due to their high powered flight and distant phylogenetic relationship. We provide quantitative data of wing musculature for 18 species of aquatic birds that can be used in future studies of muscle function during locomotion in Aves.

\section{Materials and methods}

\section{Sample and data collection}

Bird carcasses of 18 species (total of 20 individuals) of aquatic birds were obtained from loans and donations from different institutions in the United Kingdom (see Table 1 for details). A total of 18 species of waterbirds and 3 species of Anseriformes (as an outgroup) were used in this study. These species were initially assigned to functional groups by flight and foraging styles, adapted from previous classifications (Spear and Ainley 1997b; Bruderer et al. 2010; HinićFrlog and Motani 2010; Simons 2010). The following flight styles were used: "continuous flapping" (CF; e.g. cormorants, ducks and auks), "flapping/gliding" (FG; e.g. gulls), "dynamic soaring" (DS; e.g. shearwaters and gannets), and "non-flying" (NF; e.g. penguins). For foraging strategies, we used: "wing-propelled diving" (WPD; e.g. penguins and auks), "foot-propelled diving" (FPD; e.g. shags and divers), "surface feeding" (SF; that involves feeding on the water surface by seizing or filtering prey during flight or surface swimming, e.g. ducks and gulls), and "plunge diving" (PD; where birds dive into water from the air to feed, e.g. gannets). Table 1 shows details of the birds investigated in this study.

Dissections of one of the forelimbs of each specimen were performed to obtain numerical data of muscle architecture. Each individual was skinned, and muscles were identified and removed systematically from proximal to distal and extrinsic to intrinsic with any tendon and aponeurosis attached. Once removed, the muscles were weighed with a digital scale (KERN PCB, Germany) and measured with a ruler to the nearest millimetre. Muscle length (ML) was measured as the distance between the most proximal to the 
Table 1 Details of the specimens of aquatic birds used in this study. Abbreviations for institutions: RSPB, Royal Society for the Protection of Birds; NHM, Natural History Museum

\begin{tabular}{|c|c|c|c|c|c|c|}
\hline Common name & $\begin{array}{l}\text { Scientific name (Abbre- } \\
\text { viation) }\end{array}$ & Body mass (g) & Wingspan $(\mathrm{cm})$ & Flight style & Foraging strategy & Provenance \\
\hline Pink-footed goose & $\begin{array}{l}\text { Anser brachyrhynchus } \\
\text { (Ab) }\end{array}$ & $2647^{\dagger}$ & 129 & $\mathrm{CF}$ & SF & Local game keepers \\
\hline Mallard & $\begin{array}{l}\text { Anas platyrhynchos } \\
\text { (Ap) }\end{array}$ & 1357 & 81 & $\mathrm{CF}$ & $\mathrm{SF}$ & Local game keepers \\
\hline Gadwall & A. strepera (As) & 870 & 84 & $\mathrm{CF}$ & SF & Local game keepers \\
\hline Little auk & Alle alle (Aa) & 97 & $38^{\ddagger}$ & $\mathrm{CF}$ & WPD & RSPB Galloway Reserves \\
\hline Cory's shearwater & $\begin{array}{l}\text { Calonectris diomedea } \\
\text { borealis } \mathbf{( C d )}\end{array}$ & 761 & $121^{\S}$ & DS & WPD & NHM, Tring \\
\hline Rockhopper penguin & $\begin{array}{l}\text { Eudyptes moseleyi } \\
\text { (Em) }\end{array}$ & $2500^{\mathbb{I}}$ & 48.85 & NF & WPD & Museum of Scotland \\
\hline Northern fulmar & Fulmarus glacialis $(\mathbf{F g})$ & 535 & $103.5^{\dagger \dagger}$ & FG & SF & NHM, Tring \\
\hline Red-throated diver & Gavia stellata (Gs) & $1255^{\text {抹 }}$ & $111^{\text {竍 }}$ & $\mathrm{CF}$ & FPD & National Museum Cardiff \\
\hline Herring gull & Larus argentatus (La) & 788 & 120.4 & FG & SF & RSPB Galloway Reserves \\
\hline $\begin{array}{l}\text { Lesser black-backed } \\
\text { gull }\end{array}$ & Larus fuscus (Lf) & 822 & 114 & FG & SF & Cumbria Wildlife Trust \\
\hline Gannet & Morus bassanus (Mb) & 2923 & 156 & DS & PD & RSPB Galloway Reserves \\
\hline Shag & $\begin{array}{l}\text { Phalacrocorax aristote- } \\
\quad \text { lis }(\mathbf{P a})\end{array}$ & 1034 & 86.2 & $\mathrm{CF}$ & FPD & RSPB Galloway Reserves \\
\hline Manx shearwater & Puffinus puffinus (Pp) & 390 & 76.8 & DS & WPD & RSPB Galloway Reserves \\
\hline Broad-billed prion (1) & Pachyptila vittata $\mathbf{( P v )}$ & 145 & $61.5^{\S \S}$ & FG & SF & NHM, Tring \\
\hline Broad-billed prion (2) & P. vittata $(\mathbf{P v})$ & 172 & $61.5^{\S \S}$ & FG & SF & NHM, Tring \\
\hline Kittiwake (juv.) & Rissa tridactyla $(\mathbf{R t})$ & 172 & 72 & FG & SF & RSPB Galloway Reserves \\
\hline African penguin & $\begin{array}{l}\text { Spheniscus demersus } \\
\text { (Sd) }\end{array}$ & $2900^{\text {II }}$ & 44.7 & $\mathrm{NF}$ & WPD & Museum of Scotland \\
\hline Humboldt penguin & S. humboldti (Sh) & $4200^{\text {Il }}$ & 47.9 & NF & WPD & Museum of Scotland \\
\hline Guillemot (1) & Uria aalge $(\mathbf{U a})$ & 634 & 55.6 & $\mathrm{CF}$ & WPD & RSPB Galloway Reserves \\
\hline Guillemot (2) & $U$. aalge $(\mathbf{U a})$ & 556 & 58 & $\mathrm{CF}$ & WPD & RSPB Galloway Reserves \\
\hline
\end{tabular}

'Gundersen et al. (2017)

† Berg and Rayner (1995)

${ }^{\S}$ Warham (1977)

${ }^{\text {II }}$ Stonehouse (1967)

${ }^{\dagger}$ Spear and Ainley (1997a)

$\#$ Appleby et al. (1986, Bond and Gilbert 1958)

${ }^{\S}$ Harrison (2000)

most distal fibres. Fascicle length (FL) was measured by cutting the muscle belly longitudinally following the orientation of the fibres and measurements were taken from at least 5 points at different depths and a mean FL was calculated. For muscles with an insertion tendon, tendon length (TL) and tendon mass (TM) were measured after tendons were removed free from the muscles.

\section{Statistical analysis}

To investigate the scaling relations between the muscle architecture parameters of the forelimb of aquatic birds, total wing muscle mass (hereafter referred to as total wing mass) was calculated as the sum of all the muscle masses comprising the avian forelimb and compared against body mass. As total wing mass scales isometrically to body mass in all species $\left(\mathrm{y}=1.03 \mathrm{x}-1.13 ; \mathrm{R}^{2}=0.92\right), \mathrm{FL}$ and $\mathrm{TL}$ were expected to scale isometrically to muscle mass ${ }^{0.33}$ assuming geometric similarity (Alexander 2003). All the relationships between muscle architecture parameters described in this paper are based on logarithmic values. Wing muscles were grouped by their location in the forelimb segments (shoulder, brachium, antebrachium, and manus), based on where most of the mass is distributed, and by functional groups (elevators, depressors, flexors, extensors, pronators, supinators, retractors, postural, and stabilisers) following Bribiesca-Contreras et al. (2019; Table 2). An analysis of covariance (ANCOVA) was performed to evaluate whether 
Table 2 Forelimb muscles identified in the species of waterbirds used in this study. Muscles listed from proximal to distal and dorsal to ventral position. Functional groups follow Bribiesca-Contreras et al. (2019)

\begin{tabular}{|c|c|c|c|}
\hline Muscle name & Abbreviation & Region & Functional group \\
\hline Pectoralis & $\mathrm{P}$ & Shoulder & Depressor \\
\hline Supracoracoideus & $\mathrm{SC}$ & Shoulder & Elevator \\
\hline Tensor propatagialis pars longa & TPL & Brachium & Flexor \\
\hline Tensor propatagialis pars biceps & TPB & Brachium & Flexor \\
\hline Lattissimus dorsi pars cranialis & $\mathrm{LDCr}$ & Shoulder & Postural \\
\hline Lattissimus dorsi pars caudalis & LDCa & Shoulder & Extensor/Rotator \\
\hline Rhomboideus superficialis & $\mathrm{RS}$ & Shoulder & Elevator \\
\hline Rhomboideus profundus & $\mathrm{RP}$ & Shoulder & Elevator \\
\hline Serratus superficialis pars cranialis & $\mathrm{SSCr}$ & Shoulder & Stabiliser \\
\hline Serratus superficialis pars caudalis & SSCa & Shoulder & Stabiliser \\
\hline Serratus superficialis pars metapagialis & SSM & Shoulder & Flexor/Postural \\
\hline Serratus profundus & SP & Shoulder & Stabiliser \\
\hline Scapulohumeralis caudalis & $\mathrm{SHCa}$ & Shoulder & Depressor/Rotator \\
\hline Scapulohumeralis cranialis & $\mathrm{SHCr}$ & Shoulder & Rotator/Postural \\
\hline Coracobrachialis cranialis & $\mathrm{CCr}$ & Shoulder & Depressor/Rotator \\
\hline Coracobrachialis caudalis & Cca & Shoulder & Depressor/Postural \\
\hline Subcoracoideus & SBC & Shoulder & Depressor \\
\hline Subscapularis & SS & Shoulder & Depressor \\
\hline Deltoideus major & DMA & Brachium & Elevator/Rotator \\
\hline Deltoideus minor & DMI & Brachium & Elevator/Rotator/Postural \\
\hline Biceps brachii & $\mathrm{BB}$ & Brachium & Flexor/Stabiliser \\
\hline Humerotriceps & HT & Brachium & Extensor/Stabiliser \\
\hline Scapulotriceps & ST & Brachium & Rotator/Extensor/Stabiliser \\
\hline Brachialis & $\mathrm{BR}$ & Brachium & Postural \\
\hline Pronator superficialis & PS & Antebrachium & Pronator \\
\hline Pronator profundus & $\mathrm{PP}$ & Antebrachium & Supinator \\
\hline Ectepicondylo ulnaris & ECTU & Antebrachium & Supinator \\
\hline Flexor carpi ulnaris & FCU & Antebrachium & Flexor \\
\hline Flexor digitorum superficialis & FDS & Antebrachium & Extensor/Flexor/Pronator \\
\hline Flexor digitorum profundus & FDP & Antebrachium & Pronator/Flexor \\
\hline Ulnometacarpalis ventralis & UV & Antebrachium & Pronator \\
\hline Extensor carpi radialis & ECR & Antebrachium & Extensor/Postural \\
\hline Supinator & SU & Antebrachium & Supinator \\
\hline Extensor digitorum communis & EDC & Antebrachium & Extensor/Supinator \\
\hline Extensor carpi ulnaris & ECU & Antebrachium & Flexor \\
\hline Extensor longus alulae & ELA & Antebrachium & Extensor \\
\hline Extensor longus digiti majoris & ELDM & Antebrachium & Extensor \\
\hline Extensor longus digiti majoris pars distalis & ELDMd & Manus & Extensor \\
\hline Ulnometacarpalis dorsalis & UD & Manus & Flexor \\
\hline Interosseus dorsalis & ID & Manus & Elevator \\
\hline Interosseus ventralis & IV & Manus & Flexor \\
\hline Abductor alulae & $\mathrm{ABA}$ & Manus & Depressor/Extensor \\
\hline Adductor alulae & $\mathrm{ADA}$ & Manus & Flexor \\
\hline Extensor brevis alulae & EBA & Manus & Extensor \\
\hline Flexor alulae & FA & Manus & Depressor \\
\hline Abductor digiti majoris & ADM & Manus & Extensor \\
\hline Flexor digiti minoris & FDM & Manus & Flexor \\
\hline
\end{tabular}


muscle architecture parameters scale the same way in the different regions of the avian wing in all species and among the foraging and flight groups.

The muscle architecture parameters were visualized via boxplots for the locomotor groups investigated in aquatic birds. In addition, the contribution of mass by muscle functional groups, calculated as percentages of the total sum of muscle masses for each group in relation to body mass, was compared between the foraging and flight styles with an analysis of variance (ANOVA). Pairwise comparisons between the different groups were investigated via a post hoc analysis of Tukey's HSD (honestly significant different) test.

A principal component analysis (PCA) of the correlation matrix of the normalised muscle masses (muscle mass/ body mass) was performed to investigate whether variation in mass distribution differs between the foraging and flight groups, which could provide us with a functional interpretation in relation to locomotion mode.

Data analysis was performed in R version 3. 3.2 (https:// www.r-project.org/).

\section{Phylogenetic signal}

An ultrametric time version of the phylogeny from Hackett et al. (2008) was used as the backbone for this study, which was employed by Braun et al. (2011) and Han et al. (2011) and is available from the Early Bird website (https://early bird.biology.ufl.edu). The branch lengths from this tree were estimated from the tree length of the Hackett et al. (2008) tree in millions of years (MY) using non-parametric rate smoothing (Sanderson 2002). Because this phylogeny does not include all the species used in our study, we followed the method from Wang and Clarke (2014) to calculate the branch lengths for those nodes that are missing in the ultrametric tree. As species of Anseriformes were included as an outgroup, we set an extra calibration node for the divergence of Anseranas and the Anatidae at 68 MYA based on the fossil Vegavis iaai (Clarke et al. 2005). The phylogenetic relationships among species from the same family were defined from the literature (Friesen et al. 1996; Pons et al. 2005; Baker et al. 2006; Baker, Pereira and Patón 2007; Clarke et al. 2010; Ksepka and Clarke 2010; Gangloff et al. 2012). The construction of the tree was performed using the $\mathrm{R}$ package Ape (Paradis et al. 2004).

To test the effect of phylogeny on muscle mass distribution among the species of waterbirds, phylogenetic signal was calculated using the Kmult statistic (Adams 2014) on our tree of waterbirds (Online Resource 1). Kmult is a multivariate generalization of the $K$-statistic (Blomberg et al. 2003) appropriate for multivariate traits. Like $K$, values of $K$ mult equal to 1 indicate that the data fit a Brownian motion (BM) model of evolution, values of Kmult $<1$ describe traits with less phylogenetic signal than expected under BM and values of $K$ mult $>1$ indicate that close relatives are more similar than expected under BM (Blomberg et al. 2003; Adams 2014). If there was no phylogenetic signal detected, we would predict that locomotion has a greater effect on the muscle mass distribution of the forelimb of waterbirds than phylogenetic relationship. We also investigated the phylogenetic signal of body mass and wingspan using the $K$-statistic from Blomberg et al. (2003).

\section{Results}

A total of 47 muscles were identified in the flight apparatus of waterbirds and are listed in Table 2. Observations of presence/absence for muscles in different taxonomic groups were consistent to those reported elsewhere. We refer the readers to the following studies for anatomical descriptions and illustrations of forelimb myology: for penguins, see Schreiweis (1982); for Procellariformes and Gaviiformes, see McKitrick (1991); for Laridae and Alcidae, see Hudson et al. (1969); for Anatidae, we recommend consulting the works in galliform birds by Hudson and Lanzillotti (1964) and Zhang and Yang (2013). For general descriptions in Aves, see Baumel et al. (1979) and George and Berger (1966). Nomenclature follows Nomina Anatomica Avium (Baumel et al. 1979).

Fascicle length scales to muscle mass ${ }^{0.284 \pm 0.01}$ ( \pm std. error; $\mathrm{R}^{2}: 0.55, t$ value: $-4.053, p$ value: $7.93 \mathrm{E}-06$ ) in the forelimb of the species of waterbirds investigated, which significantly differs from what is expected for geometrically similar animals where longitudinal dimensions scale to mass ${ }^{0.33}$ (Fig. 1). The results of the ANCOVA indicated that the flight and foraging groups vary in their scaling relationships of FL with muscle mass along the different regions of the wing (Table 3 ).

A proximal-to-distal reduction in muscle mass is evident for all studied species, where shoulder muscle mass accounts for $\sim 80 \%$ of total single-wing mass in all the flight and foraging groups, with the non-flying penguins showing the greatest values of $96 \%$. Percentage of mass relative to total single-wing mass will be referred to as wing mass fraction from here on. Brachium and antebrachium muscle masses range from over $11 \%$ in all groups, to less than $5 \%$ in wingpropelled divers, $~ 8 \%$ in FG and PD, to 2\% in WPD. Hand musculature comprises less than $1 \%$ of wing mass fraction in all waterbirds. Shoulder mass percentage significantly differs from all the forelimb regions in all the flight and foraging groups (ANOVA and post hoc Tukey test; $p$ values $<0.05$ ). For details of the numerical values of muscle architecture parameters of the forelimb of the species of aquatic birds investigated here, see Online Resource 2. 


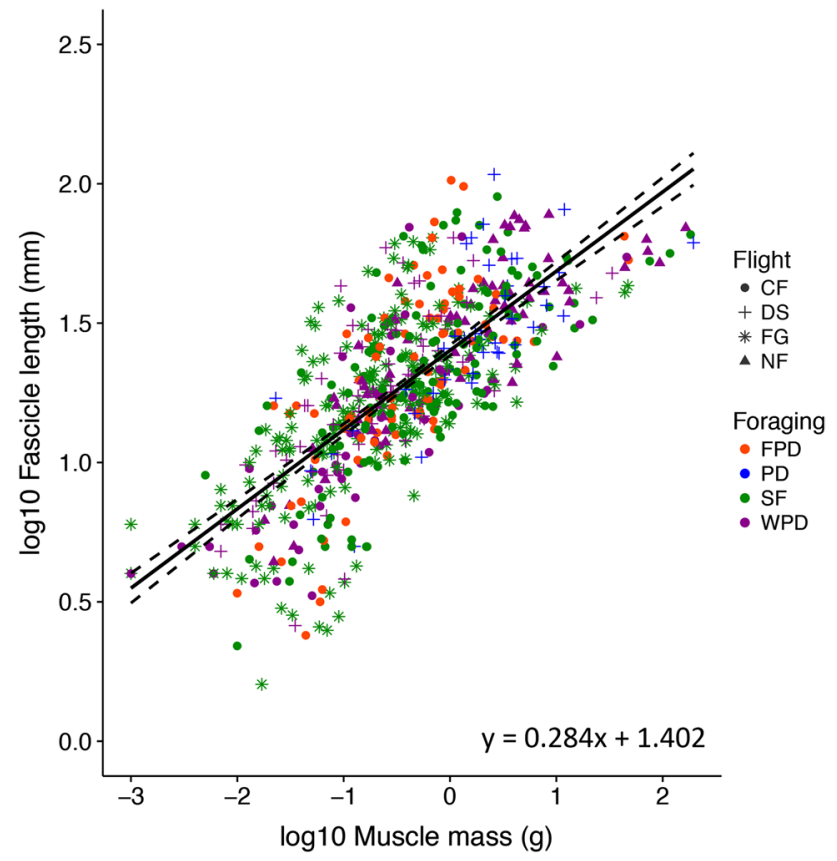

Fig. 1 Scaling relationship between $\log _{10}$ fascicle length and $\log _{10}$ muscle mass of the forelimb muscles in waterbirds. Values of fascicle lengths and muscle masses correspond to values for individual muscles in individual birds. Fit regression line (solid) and 95\% confidence interval (dashed) are drawn, and the equation of the fitted line is indicated
The mass of a single wing comprises between $~ 5 \%$ and $\sim 13 \%$ of the total body mass in the species investigated. In the flight groups, CF birds showed the greater values of single-wing mass relative to body mass $(11.14 \pm 2.86 \%$; mean \pm sd., $n=7$ ), whereas for the NF group, penguins, it comprises $8.49 \pm 2.69 \%(n=3)$ of the body mass. However, single-wing mass percentage is only significantly different between the CF and FG. In the foraging groups, the greater values of wing mass proportion correspond to the $\mathrm{PD}$ with $10.66 \%$, whereas for the foot-propelled divers, it only accounts for $6.66 \pm 1.49 \%(n=2)$ of total body mass. There are no significant differences of single-wing mass percentage among the foraging groups. The pectoralis $(\mathrm{P})$ is the largest muscle in the forelimb of all the species investigated, with values varying from $\sim 8$ and $\sim 9 \%$ in proportion to body mass in the ducks and alcids to less than $4 \%$ of total body mass in the kittiwake, fulmar, and African and Humboldt penguins. The supracoracoideus (SC) follows with values between $\sim 2 \%$ in the alcids and rockhopper penguin to less than $0.4 \%$ in the Cory's shearwater, northern fulmar, and red-throated loon. The rest of the wing musculature accounts for less than $\sim 0.5 \%$ of body mass. Figures 2 and 3 show the mass proportion of some muscles of interest in the avian wing for the flight and foraging groups, respectively. Muscles with greater values of normalised fascicle length are located in the shoulder, such as LDCr, LDCA, and SSM, whereas the distal musculature appears to have shorter fascicles.

Table 3 Statistics of the linear regression analysis for all species (bold) and ANCOVA results between flight and foraging groups ( $n$ ) by region of the muscle architecture parameters of the avian wing

\begin{tabular}{|c|c|c|c|c|c|c|c|c|c|}
\hline \multirow[b]{2}{*}{ Model } & & \multicolumn{2}{|l|}{ Shoulder } & \multicolumn{2}{|l|}{ Brachium } & \multicolumn{2}{|l|}{ Antebrachium } & \multicolumn{2}{|l|}{ Manus } \\
\hline & & $\begin{array}{l}\text { Slope } \pm \text { std. } \\
\text { error }\end{array}$ & $p$ value & $\begin{array}{l}\text { Slope } \pm \text { std. } \\
\text { error }\end{array}$ & $p$ value & $\begin{array}{l}\text { Slope } \pm \text { std. } \\
\text { error }\end{array}$ & $p$ value & $\begin{array}{l}\text { Slope } \pm \text { std. } \\
\text { error }\end{array}$ & $p$ value \\
\hline Muscle mass & vs. FL & $0.169 \pm 0.017$ & $2 \mathrm{E}-16 * * *$ & $0.212 \pm 0.019$ & 7.4E-09*** & $0.227 \pm 0.02$ & $\begin{array}{l}5.52 \mathrm{E}- \\
07 * * *\end{array}$ & $0.178 \pm 0.036$ & $4.12 \mathrm{E}-05^{* * *}$ \\
\hline \multirow[t]{4}{*}{ Flight } & $\mathrm{CF}(7)$ & $0.139 \pm 0.033$ & $\begin{array}{r}1.24 \mathrm{E}- \\
07 * * *\end{array}$ & $0.218 \pm 0.028$ & $\begin{array}{r}2.16 \mathrm{E}- \\
04 * * *\end{array}$ & $0.335 \pm 0.032$ & 0.877 & $0.192 \pm 0.06$ & $0.026^{*}$ \\
\hline & DS (3) & $0.188 \pm 0.041$ & $\begin{array}{r}1.34 \mathrm{E}- \\
03 * * *\end{array}$ & $0.175 \pm 0.043$ & $0.002 * *$ & $0.219 \pm 0.033$ & $0.002 * *$ & $0.191 \pm 0.077$ & 0.083 \\
\hline & FG (5) & $0.129 \pm 0.036$ & $\begin{array}{r}4.55 \mathrm{E}- \\
07 * * *\end{array}$ & $0.161 \pm 0.04$ & $\begin{array}{r}2.50 \mathrm{E}- \\
04^{* * *}\end{array}$ & $0.169 \pm 0.042$ & $\begin{array}{l}3.22 \mathrm{E}- \\
04 * * *\end{array}$ & $0.013 \pm 0.068$ & $3.92 \mathrm{E}-05 * * *$ \\
\hline & NF (3) & $0.097 \pm 0.045$ & $\begin{array}{r}8.86 \mathrm{E}- \\
06^{* * *}\end{array}$ & $0.278 \pm 0.067$ & 0.447 & $-0.056 \pm 0.425$ & $\begin{array}{r}3.22 \mathrm{E}- \\
04 * * *\end{array}$ & $0.388 \pm 0.101$ & 0.579 \\
\hline \multirow[t]{4}{*}{ Foraging } & FPD (2) & $0.16 \pm 0.064$ & $0.013^{*}$ & $0.075 \pm 0.055$ & $\begin{array}{r}6.78 \mathrm{E}- \\
04^{* * *}\end{array}$ & $0.277 \pm 0.083$ & 0.529 & $0.311 \pm 0.194$ & 0.925 \\
\hline & $\mathrm{PD}(1)$ & $0.147 \pm 0.074$ & $0.029 *$ & $-0.199 \pm 0.078$ & $0.002 * *$ & $0.247 \pm 0.087$ & 0.358 & $0.249 \pm 0.149$ & 0.608 \\
\hline & SF (8) & $0.13 \pm 0.027$ & $\begin{array}{r}2.06 \mathrm{E}- \\
11 * * *\end{array}$ & $0.204 \pm 0.024$ & $\begin{array}{r}3.60 \mathrm{E}- \\
06 * * *\end{array}$ & $0.192 \pm 0.027$ & $\begin{array}{l}1.82 \mathrm{E}- \\
06^{* * *}\end{array}$ & $0.117 \pm 0.053$ & $1.53 \mathrm{E}-04 * * *$ \\
\hline & WPD (7) & $0.202 \pm 0.027$ & $\begin{array}{l}7.17 \mathrm{E}- \\
06^{* * *}\end{array}$ & $0.215 \pm 0.039$ & $0.006^{* *}$ & $0.437 \pm 0.06$ & 0.083 & $0.232 \pm 0.055$ & 0.087 \\
\hline
\end{tabular}

***Indicate significant $p$ values of 0.0001 or less, **of 0.001 and $*$ of 0.01 
The percentage of mass in relation to body mass by muscle functional groups resulted in significant differences only for the elevator muscles within the flight and foraging groups. In the non-flying group, the elevator muscles accounted for $28.3 \pm 10.2 \%$ of the wing mass fraction, which significantly differed from the CF, DS, and FG (ANOVA and post hoc Tukey test; $p$ values $<0.05$ ) that present values between 10.1 to $15.78 \%$. Similarly, the wing-propelled divers showed significant differences among the other foraging groups (ANOVA and post hoc Tukey test; $p$ values $<0.05$ ) with mass proportion of $22.19 \pm 7.3 \%$ in relation to wing mass (see Online Resource 2).

PCA resulted in three principal components (PC1-PC3) that explained $74.56 \%$ of the total variance of muscle mass along the wing (Fig. 4). PC1 mostly separated the anatids
( $\mathrm{Ab}, \mathrm{Ap}, \mathrm{As})$ from penguins (Em, Sd, Sh) in opposite extremes and the rest of the species in the middle. The PC loadings are provided in Online Resource 3. This axis represented an inverse relationship with arm muscles masses (DMA, HT, ST, BB, FCU, ECR, FDP, and PS) that play a role in flexion-extension of the elbow and wrist, and rotation, stabilisation, elevation, and pronation-supination of the wing, and is positively loaded with shoulder muscles masses (SS, SC, and CCa) that assist in wing depression and elevation. PC2 mainly distinguished the anatids (Ab, Ap, As), alcids (Aa, Ua1, Ua2), and penguins from the rest of the species. PC2 positively related with proximal musculature (SHCa, P, SC, CCa, and RS) that participate in elevating, depressing, and rotating the wing. It is represented in the negative range mostly by muscles that play a role in posture
Fig. 2 Proportion of mass in relation to body mass for some muscles of interest in the forelimb of waterbirds according to flight style. a, pectoralis $(\mathrm{P})$; b, supracoracoideus $(\mathrm{SC})$; c scapulohumeralis caudalis (SHCa); d coracobrachialis caudalis (Cca); e, latissimus dorsi pars cranialis (LDCr); $\mathbf{f}$, biceps brachii (BB). Wing diagrams modified from BribiescaContreras et al. (2019)
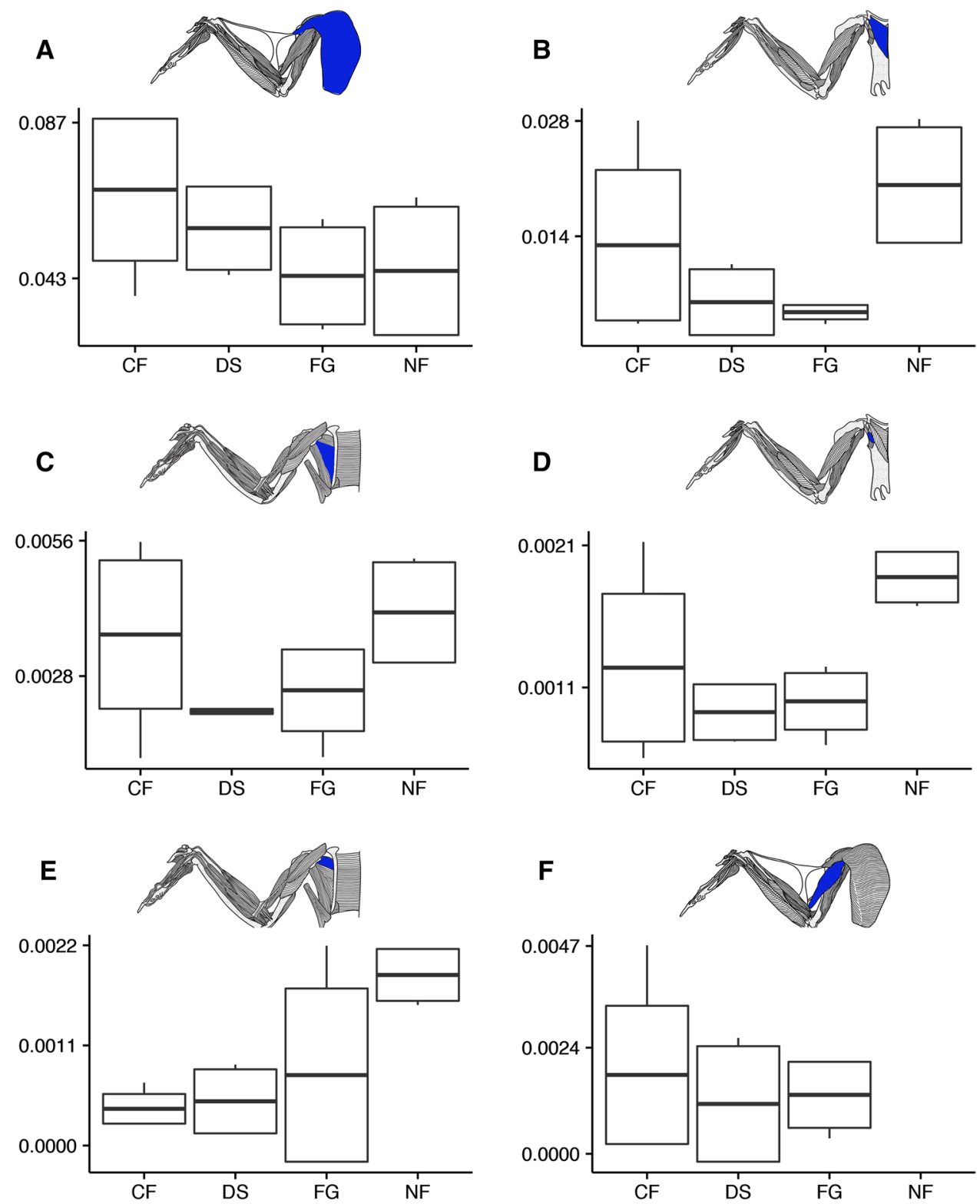
Fig. 3 Proportion of mass in relation to body mass for some muscles of interest in the forelimb of waterbirds according to foraging style. a, pectoralis (P); b, supracoracoideus (SC); c, scapulohumeralis caudalis (SHCa); d coracobrachialis caudalis (Cca); e, latissimus dorsi pars cranialis (LDCr); $\mathbf{f}$, biceps brachii (BB). Wing diagrams modified from BribiescaContreras et al. (2019)
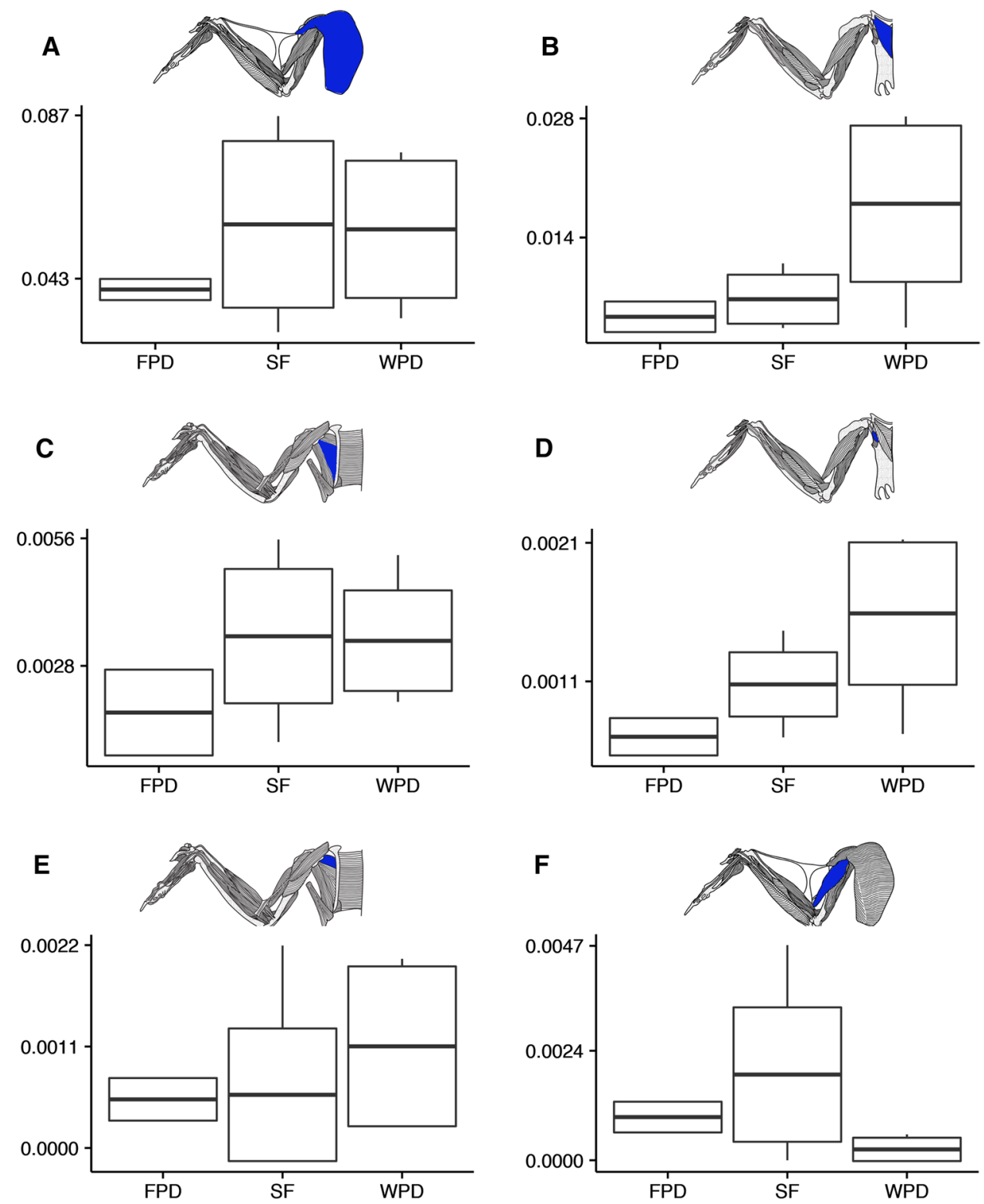

(BR) and hand motion (ADM, FCU, ELDM, EDC, and FDP), including flexion-extension of the wrist and pronation-supination of the wing. In the flight groups (Fig. 4a), most of the CF group (Aa, Ab, Ap, As, Ua1, Ua2) occupies the positive range of $\mathrm{PC} 2$ and middle range of $\mathrm{PC} 1$, indicating a larger contribution of mass for shoulder and arm musculature. The non-flying group (Em, Sd, Sh) was clustered in the extreme of $\mathrm{PC} 1$ and upper values of $\mathrm{PC} 2$ that is dominated by elevators, depressors, and rotators' muscles. The FG and DS overlap in the lower limit of PC2 and middle values of $\mathrm{PC} 1$ that is described by muscles that participate in flexion-extension of the manus and pronation-supination of the wing. In the foraging groups (Fig. $4 \mathrm{~b}$ ), most of the wingpropelled divers are clustered together with positive values of PC2 and PC1, indicating a dominance of mass proportion in muscles that are fundamental for the upstroke and downstroke. The surface-feeders are widely distributed across the full range of PC2 and negative range of PC1, where arm and hand muscles that play a role in flexion-extension and pronation-supination of the hand are considerably loaded. PD $(\mathrm{Mb})$, FPD (Gs, Pa), and two WPDs (Cd, Pp) overlap with the SF (La, Lf, Fg, Pv1, Pv2, Rt) on the lower space of PC2.

For those muscles with an insertion tendon, we calculated the mass proportion of tendon within the muscle-tendon unit (MTU) and it is presented in Online Resource 4. Contrary to muscle mass, there is no evidence of a decrease in tendon mass from the proximal to distal wing as it has been reported previously for raptor wings (Bribiesca-Contreras el al., 2019). Penguins showed an increase in tendon mass proportion in their arm and hand muscles with some MTUs 


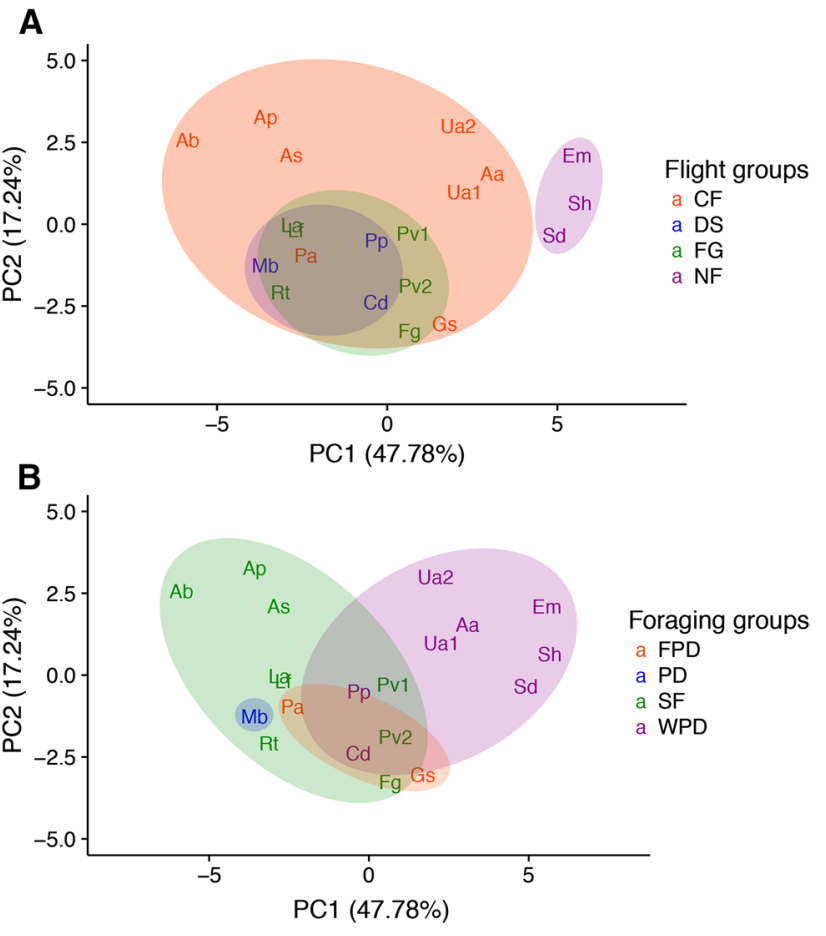

Fig. 4 Biplots of PCA of normalised muscle masses in the avian wing of flight (a) and foraging (b) groups of species of waterbirds. Abbreviations for flight groups (a) correspond to: 'constant-flapping' (FG), 'dynamic-soaring (DG), 'flap-gliding' (FG), and 'non-flying' (NF). Abbreviations for foraging groups (b) correspond to: 'foot-propelled diving' (FPD), 'plunge-diving' (PD), 'surface-feeding' (SF), and wing-propelled diving (WPD). Ellipses added to indicate flight and foraging groups. Abbreviations of species are consistent with Table 1

(FCU, FDS, FDP, EDC, ECU, ELDM, and ID) completely reduced to tendons. Among the foraging and flight groups, the contribution of tendon mass within MTUs is highly variable and difficult to interpret without any experimental data. Therefore, our discussion is focused on muscle mass as MTUs taking into account tendon proportion, and are key to infer muscle function.

Phylogenetic signal was detected for body mass ( $K$-statistics: $1.12, p$ value: $0.01,10,000$ permutations) and wingspan ( $K$-statistics: $0.89, p$ value: $0.03,10,000$ permutations), but not for the wing muscle masses (Kmult: $0.71, p$ value: $0.083,10,000$ permutations) in the forelimb of the species of aquatic birds investigated.

\section{Discussion}

\section{Scaling relationships of the wing}

Although total wing mass scales isometrically with body mass, the muscle architectural parameters in the avian wing scale differently to what is expected in geometrically similar animals, where any chosen length scales to body mass ${ }^{0.33}$. In the species of waterbirds investigated, fascicle length scaled to muscle mass ${ }^{0.284 \pm 0.01}$, indicating that as the muscles get heavier, the production of force is greater but they contract over shorter distances, and it is consistent with values reported for raptor forelimbs (Bribiesca-Contreras et al. 2019) and other groups for hindlimb muscles (e.g. Alexander 1981, Biewener 1989, 2016; Dick and Clemente 2016). Similar to previous results for mammal and bird limbs (Alexander et al. 1981; Bribiesca-Contreras et al. 2019), fascicle length scaled with muscle mass differentially along the segments of the wing (Table 3). In our work, FL in shoulder and hand scaled to muscle mass with exponent values of 0.160 and 0.178 , respectively, whereas the arm muscles showed values of $0.212-0.227$. This indicates that in the shoulder and manus, compared to the arm musculature, the fascicle length increases less rapidly and contracts over shorter distances while producing greater muscle force. Variation in the scaling relationship of the muscle architecture parameters of the wing segments is evident among the foraging and flight groups (see Table 1). Shoulder muscles significantly differed from isometric prediction in all foraging and flight groups. Penguins had the smallest scaling exponent for the shoulder muscles (0.097). In isometric animals, maximum wingbeat frequency is negatively correlated to body mass with a scaling value of -0.33 , and -0.25 in penguins, and to any chosen length $^{-1}$ (Pennycuick 1975; Johansson and Aldrin 2002). A slower increase of fascicle length in the proximal wing muscles of waterbirds would allow birds to maintain a higher wingbeat frequency in this region relative to other segments of the wing, while using smaller moment arms but maintaining the same angular range of motion (Norberg 1990). This muscle configuration in penguins would aid to maintain wingbeat frequency of a rigid wing with reduced intrinsic musculature. Additional quantitative data of wing muscles in a wider sample of birds should help to elucidate the scaling relationship of the architectural parameters that, in addition to values of moment arms, could provide insights into muscle function and its implication for locomotion. 


\section{Wing muscle mass and function}

As expected, the muscle mass distribution of the wing of these species of waterbirds reduced from proximal to distal. Mass reduction in distal musculature is an important adaptation in animal limbs (e.g. Brown et al. 2003; Payne et al. 2006; Smith et al. 2006; Wareing et al. 2011; Yang et al. 2015; Dick and Clemente 2016; Bribiesca-Contreras et al. 2019). Minimising the mass of distal muscles has the advantage of decreasing the moment of inertia, which would reduce inertial torque needed to accelerate the wing as it oscillates during flight (Hildebrand 1988; Biewener 2011).

The pectoralis is the largest muscle in the musculoskeletal system of birds, accounting for $8 \%$ to $15.5 \%$ of total body mass in flying species (Greenewalt 1962; Biewener 2011). It is a powerful pinnate muscle that acts as the main depressor of the avian wing and is capable of generating the greatest forces required for powered flight (for a review, see Biewener 2011). In our results, the proportion of mass in the pectoralis muscle ranged from over $17 \%$ of total body mass in the ducks (after doubling the values reported above for single-wing muscles), to less than $8 \%$ in the African and Humboldt penguins, fulmar and kittiwake.

In WPD (e.g. in the Atlantic puffin, Fratercula artica), the supracoracoideus muscle comprises $4-5 \%$ of total body mass whereas it accounts for only $1.6 \%$ in non-diving birds (Greenewalt 1962; Kovacs and Meyers 2000). It is hypertrophied in penguins and represents approximately $50 \%$ of the pectoralis mass (Baldwin 1988), compared to $10 \%$ of the pectoralis mass in non-diving birds and $28-30 \%$ in the Atlantic puffin (Greenewalt 1962; Kovacs and Meyers 2000). The supracoracoideus is a bipinnate muscle that elevates and supinates the wing by means of its tendon that inserts in the proximal dorsal surface of the humerus. It is activated during the upstroke at low-speed flights such as landing and taking off (Poore et al. 1997; Biewener 2011), whereas at faster flight velocities, wing elevation is enhanced by aerodynamic forces (Poore et al. 1997). In water, thrust production is observed in both downstroke and upstroke; therefore, WPD would highly benefit from having a larger supracoracoideus muscle. Evidence of the use of an active upstroke has been demonstrated in penguins and the Atlantic puffin for underwater propulsion, as well as an active thrust-generating downstroke (Clark and Bemis 1979; Johansson and Aldrin 2002). Our results indicated that the $\mathrm{SC}$ is $45.43 \pm 2.24 \%$ of the pectoralis mass in penguins, $33.22 \pm 4.51 \%$ in alcids, and $11.32 \pm 3.16 \%$ in the non-diving birds (see Fig. 2 and Fig. 3), which is consistent with previous studies (Greenewalt 1962; Baldwin 1988; Kovacs and Meyers 2000). Similarly, the P/ SC mass ratio (2.1-2.3) is consistent with what has been reported for other penguin species (Baldwin 1988). Furthermore, the mass fraction of elevator muscles is significantly greater for the NF and WPD than the other flight and foraging groups, respectively. Likewise, Kovacs and Meyers (2000) found significantly greater percentages of SC mass in relation to body mass for WPD versus FPD. $\mathrm{LDCr}$ is unusually large in the NF (Fig. 2) in comparison to the other species. This muscle consists entirely of slow tonic fibres and, with LDCa that is formed solely of fast fibres, it elevates and retracts the humerus in wing folding during perching or roosting (Hikida and Bock 1971; Rosser et al. 1994). Slow muscle fibres are commonly associated with a postural role (Goldspink 1977, 1981). However, penguin wings are modified in rigid hydrofoil-shaped flippers and no folding of the wing onto the body is needed. A study of fibre composition of wing muscles in the African penguin revealed that LDCr contained only fast fibres, which is unique in birds (Schroeder et al. 2015). This might indicate an adaptation of LDCr to assist on humeral elevation during underwater propulsion. The physiology and functional role of the LDCr in penguins, and other WPD, has yet to be investigated.

\section{Wing mass distribution and its relationship with flight and foraging style}

Distribution of muscle mass in the wing myology of birds is very diverse (Bribiesca-Contreras et al. 2019), making it difficult to understand the functional role that individual muscles play in different locomotor modes. Because mass is proportional to the amount of work that skeletal muscles can perform in a single cycle and to the maximum power output (Alexander 1992; Marsh 1999), we assessed the mass distribution as a proxy for understanding work and power generation along the wing in the species of waterbirds. We performed a PCA using the normalised muscle masses to investigate patterns of variation in mass distribution among the locomotion modes, assuming that birds sharing locomotion modes will also produce similar amounts of power in the same functional groups of muscles.

The distribution of muscle mass in the wing of the species of waterbirds used in this study showed patterns that suggest a relationship with foraging/flight styles. In the PCA biplot, three main clusters can be identified (Fig. 4). In the upper limit of PC2 axis and lower negative values of PC1, the anatids (Ab, Ap, As) are clearly distinguished from the other species. This space is mainly dominated by muscles that are active during downstroke in a variety of flight modes. These are mostly shoulder muscles (P, SHCa, and DMA) that assist in wing depression and retraction (Biewener et al. 1998; Dial et al. 1991; Dial 1992a, b), and arm muscles (BB, ST, HT, FCU, FDP, PS, and ECR) that help to flex, and extend and stabilise the elbow and wrist (Dial et al. 1988, 1991; Dial 1992a, Corvidae et al. 2006; Yang et al. 2015). These muscles are fundamental for powered flight that is characteristic of anatids (Raikow 1973). 
A second group completely separates the penguins (Em, $\mathrm{Sd}, \mathrm{Sh}$ ) and alcids (Aa, Ua1, Ua2) in a convex hull that does not overlap with the rest. The corresponding space is associated with the $\mathrm{SC}$ and muscles that depress the wing and retract the humerus ( $\mathrm{SS}, \mathrm{CCa}, \mathrm{SHCa}$ ). As mentioned above, the hypertrophy of SC is common among WPD and is correlated with the use of an active upstroke for underwater propulsion. The $\mathrm{CCa}$, in conjunction with the $\mathrm{SS}$, assists the pectoralis in humeral depression during the upstroke-downstroke transition and is in a position to supinate the wing at the end of the downstroke (Dial et al. 1991; Woolley 2000). Studies on the CCa's histochemistry in the California gull and the Atlantic puffin demonstrated that it contains a combined population of slow and fast fibres, which indicates that it could also assist the pectoralis in body support during gliding (Meyers and Mathias 1997; Kovacs and Meyers 2000). The robust CCa in penguins (see Fig. 1) might enhance the higher force production needed by the pectoralis to depress the wing in a more viscous fluid than what is required during aerial flight. It might also help to maintain the adopted 'gliding' posture of penguins during ascent (Sato et al. 2002, 2004; Takahashi et al. 2004; Watanuki et al. 2006). The presence of slow fibres in the pectoralis and supracoracoideus have been reported for the African penguin (Schroeder et al. 2015), providing further evidence of the importance of 'gliding' in penguins. In contrast, both $\mathrm{P}$ and SC consist entirely of fast fibres in $F$. artica (Kovacs and Meyers 2000) that might be associated with the constantflapping flight and high wing loading of auks (Pennycuick 1987; Bruderer et al. 2010). Additional studies are necessary to comprehensively understand the functional morphology and histochemistry of wing muscles in WPD.

A third group is identified in the middle range of PC1 and negative values of $\mathrm{PC} 2$, where the rest of the species of waterbirds overlap (Fig. 4). The FG and DS groups are fully represented in this region of the PCA biplot, in addition to the shag and red-throated loon from the CF (Fig. 4a). This space is dominated by arm musculature that assists with extension-flexion of the elbow (HT, ST) and wrist (FDP, EDC, ELDM, ADM), stabilisation and posture of the wing at the shoulder (BR, HT, ST) and wrist (ECR, FCU), and pronation and supination (ECTU, EDC, FDP) of the wing (Dial 1992a, b; Meyers 1993; Vazquez 1995). Flexion-extension and stabilisation of the wing at the elbow and wrist are fundamental for gliding and soaring birds (Meyers 1993). Analyses of the fibre type composition of the BR, triceps muscles (ST and HT) and ECR in the albatross (Meyers and Stakebake 2005), golden eagle (Meyers and McFarland 2016), California gull (Meyers and Mathias 1997), double-crested cormorant (Meyers 1997), and American kestrel (Meyers 1992) demonstrated that these muscles contain percentages of both slow and fast fibres that suggest a postural role in maintaining the wing fixed in an folded or extended position, such as gliding and soaring. Furthermore, an electromyographic study of American kestrel identified activity of the triceps muscles during gliding when extension of the elbow was observed (Meyers 1993). From an anatomical standpoint, soaring and gliding require similar positioning of the wings that explain the grouping of the FG and DS birds. A similar configuration of wing muscles was found for gliding birds of prey (Bribiesca-Contreras et al. 2019). In the case of the shag (Pa) and red-throated loon (Gs), we speculate that the sunning behaviour of cormorants and sexual/territorial displays in loons can explain a similar distribution of wing muscle mass to that of gliding and soaring birds. Cormorants exhibit a spread-wing posture to dry their wings in the sun (Henyemann 1984) that is similar to a gliding position and present populations of slow fibres in the P, CCr, DMI, ST, and ECR, as described in the doublecrested cormorant (Meyers 1997). In the common loon ( $G$. immer) and yellow-billed loon (G. adamsii), it was observed that birds can adopt an upright position with their body raising up from the water exposing the chest and holding the wings flexed or extended for a considerable amount of time during territorial and sexual displays (Sjölander and Ågren 1972, 1976).

Our results provide evidence that waterbirds sharing flight and/or foraging style also share patterns of muscle mass distribution in their forelimb. The auks, which inhabit the Northern Hemisphere and are phylogenetically unrelated to penguins, their southern counterparts, occupy a similar morphological space to them and are completely separated from other aerial flyers that includes their closer relatives, i.e., gulls (see Fig. 4). In contrast, Procellariformes (shearwaters, fulmar, and prions) clustered together with aerial flyers, excluding anatids, despite their shared ancestry with Sphenisciformes over 80 million years ago (Kaiser 2010). Therefore, it seems that locomotion style is more strongly linked to the functional anatomy of the wing than the phylogenetic relationships in the species of waterbirds investigated, although further evolutionary studies are needed to fully understand this pattern. Previous studies in a wider sample of waterbirds (excluding Charadriiformes; Wang and Clarke 2014) and Pelecaniformes (Simons 2010) demonstrated that limb proportions of skeletal elements in the avian forelimb are derived from a common evolutionary history. It is therefore interesting that, despite the conserved skeleton anatomy of the wing, it seems that muscles can exploit a wider range of functional roles, which could explain the great diversity of locomotor styles exhibited in aquatic birds.

Supplementary Information The online version of this article (https:// doi.org/10.1007/s10336-021-01868-y) contains supplementary material, which is available to authorized users.

Acknowledgements We thank Judith White and Joanne Cooper (NHM, Tring), Andrew Kitchener (Museum of Scotland), Julian Carter 
(National Museum Cardiff), Crystal Maw (RSPB Galloway Reserves), and Sarah Dalrymple (Cumbria Wildlife Trust) for the donation and loan of the specimens of waterbirds used in this study. We are also grateful to Andrew Chamberlain (UoM) and Judith and Joanne (NHM, Tring) for providing us with an appropriate space for performing dissections. This manuscript has been improved thanks to the comments from three anonymous reviewers. Funding was provided from Becas al Extranjero CONACYT (Consejo Nacional de Ciencia y Tecnología).

Open Access This article is licensed under a Creative Commons Attribution 4.0 International License, which permits use, sharing, adaptation, distribution and reproduction in any medium or format, as long as you give appropriate credit to the original author(s) and the source, provide a link to the Creative Commons licence, and indicate if changes were made. The images or other third party material in this article are included in the article's Creative Commons licence, unless indicated otherwise in a credit line to the material. If material is not included in the article's Creative Commons licence and your intended use is not permitted by statutory regulation or exceeds the permitted use, you will need to obtain permission directly from the copyright holder. To view a copy of this licence, visit http://creativecommons.org/licenses/by/4.0/.

\section{References}

Adams DC (2014) A generalized k statistic for estimating phylogenetic signal from shape and other high-dimensional multivariate data. Syst Biol 63:685-697

Alexander RM (1992) The work that muscles can do. Nature 357:360-361

Alexander RMcN, Jayes AS, Maloiy GMO, Wathuta EM, (1981) Allometry of the leg muscles of mammals. J Zool 194:539-552

Alexander RMN (2003) Principles of animal locomotion. Princeton University Press, Princeton

Appleby R, Madge SC, Mullarney K (1986) Identification of divers in immature and winter plumages. Brit Birds 79:365-391

Ashmole NP (1971) Seabird ecology and the marine environment. In: Farner DS, King JR (eds) Avian biology, vol 1. Academic Press, New York, pp 223-286

Baker AJ, Pereira SL, Haddrath OP, Edge K-A (2006) Multiple gene evidence for expansion of extant penguins out of Antarctica due to global cooling. P Roy Soc B-Biol Sci 273:11-17

Baker AJ, Pereira SL, Paton TA (2007) Phylogenetic relationships and divergence times of Charadriiformes genera: multigene evidence for the Cretaceous origin of at least 14 clades of shorebirds. Biol Lett 3:205-210

Baldwin J (1988) Predicting the swimming and diving behaviour of penguins from muscle biochemistry. Hydrobiologia 165:255-261

Bannasch R (1995) Hydrodynamics of penguins-an experimental approach. In: Dann P, Norman I, Reilly P (eds) The penguins: ecology and management. Surrey Beatty \& Sons, Melbourne, pp 141-176

Baumel JJ, King A, Lucas A et al (1979) Nomina anatomica avium. An annotated anatomical dictionary of birds. Academic Press, London

Berg C, Rayner J (1995) The moment of inertia of bird wings and the inertial power requirement for flapping flight. J Exp Biol 198:1655-1664

Biewener AA (1989) Mammalian terrestrial locomotion and size. Bioscience 39:776-783

Biewener AA, Corning WR, Tobalske BW (1998) In vivo pectoralis muscle force-length behavior during level flight in pigeons (Columba livia). J Exp Biol 201:3293-3307
Biewener AA (2011) Muscle function in avian flight: achieving power and control. P Roy Soc B-Biol Sci 366:1496-1506

Biewener AA (2016) Locomotion as an emergent property of muscle contractile dynamics. J Exp Biol 219:285-294

Blomberg SP, Garland T, Ives AR, Crespi B (2003) Testing for phylogenetic signal in comparative data: behavioral traits are more labile. Evolution 57:717-745

Bond CF, Gilbert PW (1958) Comparative study of blood volume in representative aquatic and nonaquatic birds. Am J Physiol 194:519-521

Braun EL, Kimball RT, Han K-L et al (2011) Homoplastic microinversions and the avian tree of life. BMC Evol Biol 11:141

Brewer ML, Hertel F (2007) Wing morphology and flight behavior of pelecaniform seabirds. J Morphol 268:866-877

Bribiesca-Contreras F, Parslew B, Sellers WI (2019) A quantitative and comparative analysis of the muscle architecture of the forelimb myology of diurnal birds of prey (Order Accipitriformes and Falconiformes). Anat Rec 302:1808-1823

Brown NAT, Kawcak CE, McIlwraith CW, Pandy MG (2003) Architectural properties of distal forelimb muscles in horses, Equus caballus. J Morphol 258:106-114

Brown RGB, Bourne WRP, Wahl TR (1978) Diving by Shearwaters. The Condor 80:123-125

Bruderer B, Peter D, Boldt A, Liechti F (2010) Wing-beat characteristics of birds recorded with tracking radar and cine camera. Ibis 152:272-291

Clark BD, Bemis W (1979) Kinematics of swimming of penguins at the Detroit Zoo. J Zool 188:411-428

Clarke JA, Ksepka DT, Salas-Gismondi R et al (2010) Fossil evidence for evolution of the shape and color of penguin feathers. Science 330:954-957

Clarke JA, Tambussi CP, Noriega JI et al (2005) Definitive fossil evidence for the extant avian radiation in the Cretaceous. Nature 433:305-308

Corvidae EL, Bierregaard RO, Peters SE (2006) Comparison of wing morphology in three birds of prey: correlations with differences in flight behavior. J Morphol 267:612-622

Croxall JP, Naito Y, Kato A et al (1991) Diving patterns and performance in the Antarctic blue-eyed shag Phalacrocorax atriceps. J Zool 225:177-199

Denny MW (1993) Air and water: the biology and physics of life's media. Princeton University Press, Princeton

Dial KP (1992a) Avian forelimb muscles and nonsteady flight: can birds fly without using the muscles in their wings? Auk 109:874-885

Dial KP (1992b) Activity patterns of the wing muscles of the pigeon (Columba livia) during different modes of flight. J Exp Zool 262:357-373

Dial KP, Goslow GE, Jenkins FA (1991) The functional anatomy of the shoulder in the European starling (Sturnus vulgaris). J Morphol 207:327-344

Dial KP, Kaplan SR, Goslow GE, Jenkins FA (1988) A functional analysis of the primary upstroke and downstroke muscles in the domestic pigeon (Columba livia) during flight. J Exp Biol 134:1-16

Dick TJM, Clemente CJ (2016) How to build your dragon: scaling of muscle architecture from the world's smallest to the world's largest monitor lizard. Front Zool 13:1-17

Elliott KH, Ricklefs RE, Gaston AJ et al (2013) High flight costs, but low dive costs, in auks support the biomechanical hypothesis for flightlessness in penguins. PNAS 110:9380-9384

Elliott KH, Shoji A, Campbell KL, Gaston AJ (2010) Oxygen stores and foraging behavior of two sympatric, planktivorous alcids. Aquat Biol 8:221-235 
Friesen VL, Baker AJ, Piatt JF (1996) Phylogenetic relationships within the Alcidae (Charadriiformes: Aves) inferred from total molecular evidence. Mol Biol Evol 13:359-367

Gangloff B, Shirihai H, Watling D et al (2012) The complete phylogeny of Pseudobulweria, the most endangered seabird genus: systematics, species status and conservation implications. Conserv Genet 13:39-52

George J, Berger A (1966) Avian myology. Academic Press, New York

Goldspink G (1981) The use of muscles during flying, swimming, and running from the point of view of energy saving. Symp Zool Soc Lond 48:219-238

Goldspink G (1977) Muscle energetics and animal locomotion. In: Alexander RM, Goldspink G (eds) Mechanics and energetics of animal locomotion. Chapman and Hall, London, pp 57-81

Goldspink G, Mills C, Schmidt-Nielsen K (1978) Electrical activity of the pectoral muscles during gliding and flapping flight in the herring gull (Larus argentatus). Experientia 34:862-865

Greenewalt CH (1962) Dimensional relationships for flying animals. Smithson Misc Collect 144:1-46

Gundersen OM, Clausen KK, Madsen J (2017) Body mass dynamics of pink-footed geese (Anser brachyrhynchus) during stopover on autumn migration in Norway. Waterbirds 40:353-362

Habib M (2010) The structural mechanics and evolution of aquaflying birds. Biol J Linn Soc 99:687-698

Hackett SJ, Kimball RT, Reddy S et al (2008) A phylogenomic study of birds reveals their evolutionary history. Science 320:1763-1768

Han K-L, Braun EL, Kimball RT et al (2011) Are transposable element insertions homoplasy free?: an examination using the avian tree of life. Syst Biol 60:375-386

Harrison P (2000) Seabirds: an identification guide. Houghton Mifflin Harcourt, Boston

Hartman FA (1961) Locomotor mechanisms of birds. Smithsonian Miscellaneous Collections 143(1):1-91

Hedenström A (2008) Adaptations to migration in birds: behavioural strategies, morphology and scaling effects. Philos Trans R Soc Lond B Biol Sci 363:287-299

Henyemann WW (1984) Spread-winged behaviour of Double-crested and Flightless Cormorants Phalacrocorax auritus and P. harrisi: wing drying or thermoregulation? Ibis 126:230-239

Hikida RS, Bock WJ (1971) Innervation of the avian tonus latissimus dorsi anterior muscle. Am J Anat 130:269-279

Hildebrand M (1988) Form and function in vertebrate feeding and locomotion1. Am Zool 28(2):727-738

Hinić-Frlog S, Motani R (2010) Relationship between osteology and aquatic locomotion in birds: determining modes of locomotion in extinct Ornithurae. J Evol Biol 23:372-385

Hudson GE, Hoff KM, Berge JV, Trivette EC (1969) A Numerical study of the wing and leg muscles of Labi and Alcae. Ibis 111:459-524

Hudson GE, Lanzillotti PJ (1964) Muscles of the pectoral limb in galliform birds. Am Midl Nat 71:1-113

Johansson LC, Aldrin BSW (2002) Kinematics of diving Atlantic puffins (Fratercula arctica L.): evidence for an active upstroke. J Exp Biol 205:371-378

Kaiser GW (2010) The inner bird: anatomy and evolution. UBC Press, Vancouver \& Toronto

Klages NTW, Cooper J (1992) Bill morphology and diet of a filterfeeding seabird: the broad-billed prion Pachyptila vittata at South Atlantic Gough Island. J Zool 227:385-396

Kovacs CE, Meyers RA (2000) Anatomy and histochemistry of flight muscles in a wing-propelled diving bird, the Atlantic puffin, Fratercula arctica. J Morphol 244:109-125
Ksepka DT, Clarke JA (2010) The basal penguin (Aves, Sphenisciformes) Perudyptes devriesi and a phylogenetic evaluation of the penguin fossil record. Bull Am Mus Nat Hist 337:1-77

Kuroda N (1954) On the classification and phylogeny of the Order Tubinares, particularly the shearwaters (Puffinus), with special considerations on their osteology and habit differentiation. Herald Co., Tokyo

Lieber RL, Fridén J (2000) Functional and clinical significance of skeletal muscle architecture. Muscle Nerve 23:1647-1666

Livezey BC (1989) Morphometric patterns in Recent and fossil penguins (Aves, Sphenisciformes). J Zool 219:269-307

Livezey BC (1988) Morphometrics of flightlessness in the Alcidae. Auk 105:681-698

Lovvorn JR, Jones DR (1991) Body mass, volume, and buoyancy of some aquatic birds, and their relation to locomotor strategies. Can J Zool 69:2888-2892

Lovvorn JR, Jones DR (1994) Biomechanical conflicts between adaptations for diving and aerial flight in estuarine birds. Estuaries $17: 62-75$

Marsh RL (1999) How muscles deal with real-world loads: the influence of length trajectory on muscle performance. J Exp Biol 202:3377-3385

McKitrick MC (1991) Forelimb myology of loons (Gaviiformes), with comments on the relationship of loons and tubenoses (Procellariiformes). Zool J Linn Soc 102:115-152

Meyers RA (1993) Gliding flight in the American Kestrel (Falco sparverius): an electromyographic study. J Morphol 215:213-224

Meyers RA (1997) Anatomy and histochemistry of spread-wing posture in birds. I. Wing drying posture in the double-crested cormorant Phalacrocorax auritus. J Morphol 233:67-76

Meyers RA (1992) The morphological basis of folded-wing posture in the American Kestrel, Falco sparverius. Anat Rec 232:493-498

Meyers RA, Mathias E (1997) Anatomy and histochemistry of spreadwing posture in birds. 2. Gliding flight in the California gull, Larus californicus: a paradox of fast fibers and posture. J Morphol 233:237-247

Meyers RA, McFarland JC (2016) Anatomy and histochemistry of spread-wing posture in birds. 4. Eagles soar with fast, not slow muscle fibres. Acta Zool 97:319-324

Meyers RA, Stakebake EF (2005) Anatomy and histochemistry of spread-wing posture in birds. 3. Immunohistochemistry of flight muscles and the "shoulder lock" in albatrosses. J Morphol 263:12-29

Nelson B (1978) The Sulidae: gannets and boobies. Oxford University Press, Oxford

Norberg UM (1990) Vertebrate flight: mechanics, physiology, morphology, ecology and evolution. Springer, Berlin

Paradis E, Claude J, Strimmer K (2004) APE: Analyses of phylogenetics and evolution in R language. Bioinformatics 20:289-290

Payne RC, Crompton RH, Isler K et al (2006) Morphological analysis of the hindlimb in apes and humans. I. Muscle architecture. J Anat 208:709-724

Pennycuick C (1975) Mechanics of flight. In: Farner DS, King JR (eds) Avian biology, vol 5. Academic Press, New York \& London, pp 1-75

Pennycuick CJ (1982) The Flight of Petrels and Albatrosses (Procellariiformes), Observed in South Georgia and its Vicinity. Philos Trans R Soc Lond B Biol Sci 300:75-106

Pennycuick CJ (1987) Flight of Auks (Alcidae) and Other Northern Seabirds Compared with Southern Procellariiformes: Ornithodolite Observations. J Exp Biol 128:335-347

Pennycuick CJ (1989) Bird flight performance: a practical calculation manual. Oxford University Press, Oxford 
Ponganis PJ, Costello ML, Starke LN et al (1997) Structural and biochemical characteristics of locomotory muscles of emperor penguins, Aptenodytes forsteri. Respir Physiol 109:73-80

Pons J-M, Hassanin A, Crochet P-A (2005) Phylogenetic relationships within the Laridae (Charadriiformes: Aves) inferred from mitochondrial markers. Mol Phylogenetics Evol 37:686-699

Poore SO, Ashcroft A, Sánchez-Haiman A, Goslow GE (1997) The contractile properties of the $M$. supracoracoideus in the pigeon and starling: a case for long-axis rotation of the humerus. J Exp Biol 200(23):2987-3002

Raikow RJ (1973) Locomotor mechanisms in north american ducks. Wilson J Ornithol 85:295-307

Raikow RJ, Bicanovsky L, Bledsoe AH (1988) Forelimb joint mobility and the evolution of wing-propelled diving in birds. Auk 105:446-451

Rayner JMV (1988) Form and function in avian flight. In: Johnston RF (ed) Current ornithology. Springer, US, Boston, MA, pp 1-66

Ropert-Coudert Y, Grémillet D, Ryan P et al (2004) Between air and water: the plunge dive of the Cape Gannet Morus capensis. Ibis 146:281-290

Rosser BWC, Waldbillig DM, Wick M, Bandman E (1994) Muscle fiber types in the pectoralis of the white pelican, a soaring bird. Acta Zool 75:329-336

Sanderson MJ (2002) Estimating absolute rates of molecular evolution and divergence times: a penalized likelihood approach. Mol Biol Evol 19:101-109

Sato K, Charrassin J-B, Bost C-A, Naito Y (2004) Why do macaroni penguins choose shallow body angles that result in longer descent and ascent durations? J Exp Biol 207:4057-4065

Sato K, Naito Y, Kato A et al (2002) Buoyancy and maximal diving depth in penguins: do they control inhaling air volume? J Exp Biol 205:1189-1197

Schreiweis DO (1982) A comparative study of the appendicular musculature of penguins (Aves: Sphenisciformes). Smithson Contrib Zool 1-46.

Schroeder KL, Sylvain NJ, Kirkpatrick LJ, Rosser BWC (2015) Fibre types in primary 'flight' muscles of the African Penguin (Spheniscus demersus). Acta Zool 96:510-518

Sievwright H, Macleod N (2012) Eigensurface analysis, ecology, and modelling of morphological adaptation in the falconiform humerus (Falconiformes: Aves). Zool J Linn Soc 165:390-419

Simons ELR (2010) Forelimb skeletal morphology and flight mode evolution in pelecaniform birds. Zool 113:39-46

Sjölander S, Ågren G (1976) Reproductive behavior of the Yellowbilled Loon, Gavia adamsii. Condor 78:454-463

Sjölander S, Agren G (1972) Reproductive Behavior of the Common Loon. Wilson J Ornithol 84:296-308

Smith NC, Wilson AM, Jespers KJ, Payne RC (2006) Muscle architecture and functional anatomy of the pelvic limb of the ostrich (Struthio camelus). J Anat 209:765-779

Spear LB, Ainley DG (1997a) Flight behaviour of seabirds in relation to wind direction and wing morphology. Ibis 139:221-233

Spear LB, Ainley DG (1997b) Flight speed of seabirds in relation to wind speed and direction. Ibis 139:234-251
Spring L (1971) A Comparison of Functional and Morphological Adaptations in the Common Murre (Uria aalge) and ThickBilled Murre (Uria lomvia). Condor 73:1-27

Stettenheim P (1959) Adaptations for Underwater Swimming in the Common Murre (Uria aalge). Dissertation, The University of Michigan

Stonehouse B (1967) The general biology and thermal balances of penguins. In: Cragg JB (ed) Advances in ecological research. Academic Press, London \& New York, pp 131-196

Storer RW (1960) Evolution in the diving birds. Acta XVIII Congr Int Ornithol 2:694-707

Takahashi A, Sato K, Naito Y et al (2004) Penguin-mounted cameras glimpse underwater group behaviour. Proc Biol Sci 271:S281-S282

Torrella JR, Fouces V, Palomeque J, Viscor G (1998) Comparative skeletal muscle fibre morphometry among wild birds with different locomotor behaviour. J Anat 192:211-222

Townsend CW (1909) The use of the wings and feet by diving birds. Auk 26:234-248

Vazquez RJ (1995) Functional anatomy of the pigeon hand (Columba livia): a muscle stimulation study. J Morphol 226:33-45

Vogel S (1994) Life in moving fluids. Princeton University Press, Princeton

Wang X, Clarke JA (2014) Phylogeny and forelimb disparity in waterbirds. Evolution 68:2847-2860

Wareing K, Tickle PG, Stokkan K-A et al (2011) The musculoskeletal anatomy of the reindeer (Rangifer tarandus): fore- and hindlimb. Polar Biol 34:1571-1578

Warham J (1977) Wing loadings, wing shapes, and flight capabilities of procellariiformes. New Zeal J Zool 4:73-83

Watanuki Y, Takahashi A, Daunt F et al (2005) Regulation of stroke and glide in a foot-propelled avian diver. J Exp Biol 208:2207-2216

Watanuki Y, Wanless S, Harris M et al (2006) Swim speeds and stroke patterns in wing-propelled divers: a comparison among alcids and a penguin. J Exp Biol 209:1217-1230

Weimerskirch H, Cherel Y (1998) Feeding ecology of short-tailed shearwaters: breeding in Tasmania and foraging in the Antarctic? Mar Ecol Prog Ser 167:261-274

Woolley JD (2000) The functional morphology of the avian flight muscle $M$. Coracobrachialis posterior. J Exp Biol 203:1767-1776

Yang Y, Wang H, Zhang Z (2015) Muscle architecture of the forelimb of the Golden Pheasant (Chrysolophus pictus) (Aves: Phasianidae) and its implications for functional capacity in flight. Avian Res 6:1-8

Zhang Z, Yang Y (2013) Forelimb Myology of the Golden Pheasant (Chrysolophus pictus). Int J Morphol 31:1482-1490

Publisher's Note Springer Nature remains neutral with regard to jurisdictional claims in published maps and institutional affiliations. 